\title{
Pharmacodynamic and Pharmacokinetic Drug Interaction Of Gliclazide and Olanzapine in Animal Models
}

\author{
Eswar Kumar K ${ }^{1}$, Raghu Ram K ${ }^{2}$, Swathi $\mathrm{P}^{3}$, Jyotsna Rani $\mathrm{P}^{4}$ and Gupta M.N ${ }^{5}$ \\ 1,2,3,4,5 (Pharmacology Division, A.U. College of Pharmaceutical Sciences,Andhra University, Andhra Pradesh, India)
}

\begin{abstract}
Studies were conducted in normal rats, alloxan induced diabetic rats and normal rabbits with oral administration of selected doses of gliclazide, olanzapine and their combination with adequate wash out periods in between treatments. Blood samples were collected from rats and rabbits at regular intervals of time and were analysed for glucose by GOD/POD method and for gliclazide by HPLC method. Glicazide produced hypoglycemia and antihyperglycemia in normal/diabetic rats with peak activity at $1 \mathrm{~h} \& 8 \mathrm{~h}$ and $3 \mathrm{~h} \& 10 \mathrm{~h}$ respectively and in rabbits at $2 \mathrm{~h}$. Therapeutic dose of olanzapine alone did not alter the normal blood glucose level and it did not alter the hypoglycemic response produced by gliclazide in combination. The same phenomenon observed in diabetic rats and rabbits also. There was no significant change in the serum levels and pharmacokinetic parameters of gliclazide when given in combination with olanzapine in normal rabbits. Hence it is concluded that single dose treatment with olanzapine has no influence on pharmacodynamics/ pharmacokinetics of gliclazide. Since the combination was found to be safe in two dissimilar species, the combination might be safe in humans also.
\end{abstract}

Keywords:-Drug interactions, Gliclazide, Olanzapine, Pharmacodynamics and Pharmacokinetics.

\section{Introduction:}

Now a days use of more than one drug (Polypharmacy) is a common practice to treat the chronic disorders like diabetes mellitus, hypertension etc. Polypharmacy is quite common practice all over the world to treat single disorder and multiple disorders which occur simultaneously. In such a situation one drug may interact with other drug leading to drug drug interactions. These interactions are more serious with high risk disorders like diabetes, hypertension or high risk drugs like antidiabetic, antihypertensive, antiarrhythmic drugs etc.

Diabetes mellitus is one such disorder which requires careful management of its therapy with respect to blood glucose levels. There are reports for the development of diabetes mellitus in patients with CNS disorders like depression and schizophrenia [1] [2]. In such situations there is every possibility for the use of multiple drug therapy i.e; anti diabetic drugs with drugs for the treatment of other associated disorders and these situations may lead to drug-drug interaction problems. Maintenance of normal blood glucose levels is essential in diabetes since a decrease in blood glucose levels (hypoglycemia) or increase in blood glucose levels (hyperglycemia) is unwanted phenomenon. Hence monitoring of anti diabetic drug therapy in presence of other drugs is very much needed in order to maintain the safety.

There are several reports that prevalence of type II diabetes in people with schizophrenia may be 2-4times higher than general population [3] and on chronic usage of atypical antipsychotic drugs may develop diabetes like conditions (hyperglycemia) [4] [5]. Oral hypoglycaemic agents are used in the treatment of type II diabetes, amongst which gliclazide, a second generation sulfonyl urea derivative is preferred in the therapy because of its selective inhibitory activity towards pancreatic $\mathrm{K}^{+}$ATP channels, [6] [7] [8], antioxidant property, [9] [10] [11], low incidence of producing severe hypoglycaemia [12] [13] and other haemobiological effects [14] [15] [16]. Gliclazide induces the release of insulin by triggering calcium entry into the pancreatic $\beta$ cells by blocking $\mathrm{K}^{+}$channels. Our earlier studies indicate interaction of gliclazide with several other classes of drugs [17] [18] [19] [20] [21]. Among atypical antipsychotic drugs olanzapine is most widely used to treat schizophrenia. The protein binding of gliclazide and olanzapine are 85-99\% and 93\% respectively and glucuronidation is one of the metabolic pathway involved in both the drugs [22] [23]. Since there is a possibility for their combined use in schizophrenia associated with diabetes mellitus and there is a chance of 
interaction at distribution and metabolism it was planned to find out the safety of the combination in animal models. Hence in the present study the influence of olanzapine on the pharmacodynamics and pharmacokinetics of gliclazide was carried out in rats/rabbits.

\section{Materials and Methods}

Albino rats of either sex obtained from M/s. Mahaveer Enterprises, Hyderabad and albino rabbits of either sex obtained from M/s. Ghosh Enterprises, Kolkata were used in the study. All animals were maintained on pellet diet supplied by M/s. Rayan Biotechnologies Pvt. Ltd., Hyderabad with $12 \mathrm{~h} / 12 \mathrm{~h}$ light/dark cycle and water ad libitum. Animals were fasted for $18 \mathrm{~h}$ before the experiment.

\subsection{Study in normal rats:}

A group of six albino rats weighing between $250-300 \mathrm{~g}$ were administered with $1 \mathrm{mg} / \mathrm{kg}$ body weight gliclazide, orally. The same group was administered with $0.9 \mathrm{mg} / \mathrm{kg}$ body weight olanzapine, orally after a wash out period of one week. The same group was also administered with $0.9 \mathrm{mg} / \mathrm{kg}$ body weight olanzapine $30 \mathrm{~min}$ prior to $1 \mathrm{mg} / \mathrm{kg}$ body weight gliclazide, after a further wash out period of 1 week. Blood samples were withdrawn from retro orbital puncture at $0,1,2,3,4,6,8,10$ and $12 \mathrm{~h}$ intervals. Blood samples were analysed for blood glucose levels by GOD/POD method [24] using commercial glucose kits (Span diagnostics).

\subsection{Study in diabetic rats:}

Diabetes was induced by the administration of alloxan monohydrate in two doses i.e.; $100 \mathrm{mg}$ and $50 \mathrm{mg} / \mathrm{kg}$ body weight intraperitoneally for two consecutive days [25]. A group of 6 rats with blood glucose levels above $250 \mathrm{mg} / \mathrm{dL}$ was selected for the study. The study similar to the one conducted in normal rats was repeated in diabetic group.

\subsection{Study in normal rabbits:}

A group of six albino rabbits weighing between 1.38-1.7 kg were used in the study. They were administered with 5.6 $\mathrm{mg} / 1.5 \mathrm{~kg}$ body weight gliclazide orally. The same group was administered with $0.7 \mathrm{mg} / 1.5 \mathrm{~kg}$ body weight olanzapine orally after a wash out period of 1 week. The same group was also administered with $0.7 \mathrm{mg} / 1.5 \mathrm{~kg}$ body weight olanzapine (single dose treatment) $30 \mathrm{~min}$ prior to $5.6 \mathrm{mg} / 1.5 \mathrm{~kg}$ body weight gliclazide after a further was out period of one week. Blood samples were collected at $0,1,2,3,4,6,8,12,16$ and $24 \mathrm{~h}$ intervals by puncturing the marginal ear vein in all the experiments. Blood samples were analysed for blood glucose levels by GOD/POD method [24] using commercial glucose kits and for serum gliclazide concentration by HPLC method [26].

The animal experiments were approved by our Institutional Animal Ethics committee and by the Government regulatory body for animal research (Regd. No. 516/01/A/CPCSEA).

\subsection{Data and Statistical analysis:}

Data was expressed as Mean \pm Standard Error Mean (SEM). The significance was determined by applying students paired ' $\mathrm{t}$ ' test.

\section{Results}

Gliclazide produced a biphasic response with peak hypoglycemic activities at 1 and $8 \mathrm{~h}$ in normal rats and at 3 and $10 \mathrm{~h}$ in diabetic rats, whereas it produced a single peak at $2 \mathrm{~h}$ in normal rabbits. Therapeutic dose of olanzapine alone did not alter the normal blood glucose level and it did not alter the hypoglycemic response produced by gliclazide in combination. The same phenomenon observed in diabetic rats also.

Single dose treatment of olanzapine given $30 \mathrm{~min}$ prior to gliclazide neither altered pharmacodynamic nor pharmacokinetic parameters of gliclazide in normal rabbits. There was no statistical significant interaction of gliclazide with olanzapine combination when compared to gliclazide control in the following parameters like $\mathrm{K}_{\mathrm{a}}, \mathrm{t}_{\max }, \mathrm{C}_{\max }, \mathrm{AUC}$, AUMC, t1/2, MRT, Vd and clearance. 


\section{Discussion}

Drug interactions are usually seen in clinical practice and the mechanisms of interactions are evaluated usually in animal models. We studied the influence of olanzapine on the pharmacodynamics of gliclazide in normal/diabetic rats and in normal rabbits and on the pharmacokinetics of gliclazide in normal rabbits. The normal rat model served to quickly identify the interaction. The diabetic rat model served to validate the same response in the actually used condition of the drug (in type II diabetes). The rabbit model is another dissimilar species to validate the occurrence of interaction in another species. It is well established that gliclazide acts by both pancreatic (Insulin release by $\mathrm{K}^{+}$channel inhibition in $\beta$ cells) and extra pancreatic (tissue uptake of glucose) mechanisms. The target for sulfonylurea activity is ATP sensitive $\mathrm{K}^{+}$channels ( $\mathrm{K}^{+}$ATP channels). The sulfonylureas and related drugs used in type II diabetes stimulate insulin by closing $\mathrm{K}^{+} \mathrm{ATP}$ channels in pancreatic $\beta$ cells. The sulfonylureas target the SUR (sulfonylurea receptor) subunit of $\mathrm{K}^{+} \mathrm{ATP}$ channels, which exists in several iso forms expressed in different tissues, SUR1 in pancreatic $\beta$ cells, SUR2A in cardiac muscle and SUR2B in vascular smooth muscle [27]. The pancreatic cell ATP increases when plasma glucose level rises resulting in the closure of $\mathrm{K}^{+} \mathrm{ATP}$ channels in plasma membrane, allows the cell to depolarize, triggering $\mathrm{Ca}^{+2}$ entry and insulin release [28].

Olanzapine is an atypical antipsychotic drug widely used for the treatment of schizophrenia. The dose of olanzapine is selected by human therapeutic dose extrapolated to rats basing on the body surface area. The gliclazide produced biphasic response in rat model may be due to its enterohepatic circulation in rats [29] [30] and in humans [31]. The selected dose of olanzapine produced a slight reduction in the blood glucose levels which was found to be insignificant. In combination it didn't alter the blood glucose reduction produced by gliclazide. Single dose treatment of olanzapine given 30 min prior to gliclazide did not alter the pharmacokinetic parameters of gliclazide in normal rabbits. There was no statistical significance of gliclazide with olanzapine combination when compared to gliclazide control in the following parameters like $\mathrm{K}_{\mathrm{a}}, \mathrm{t}_{\max }, \mathrm{C}_{\max }$, AUC, AUMC, $\mathrm{t}_{1 / 2}, \mathrm{MRT}, \mathrm{Vd}$ and clearance.

\section{Figures and Tables}
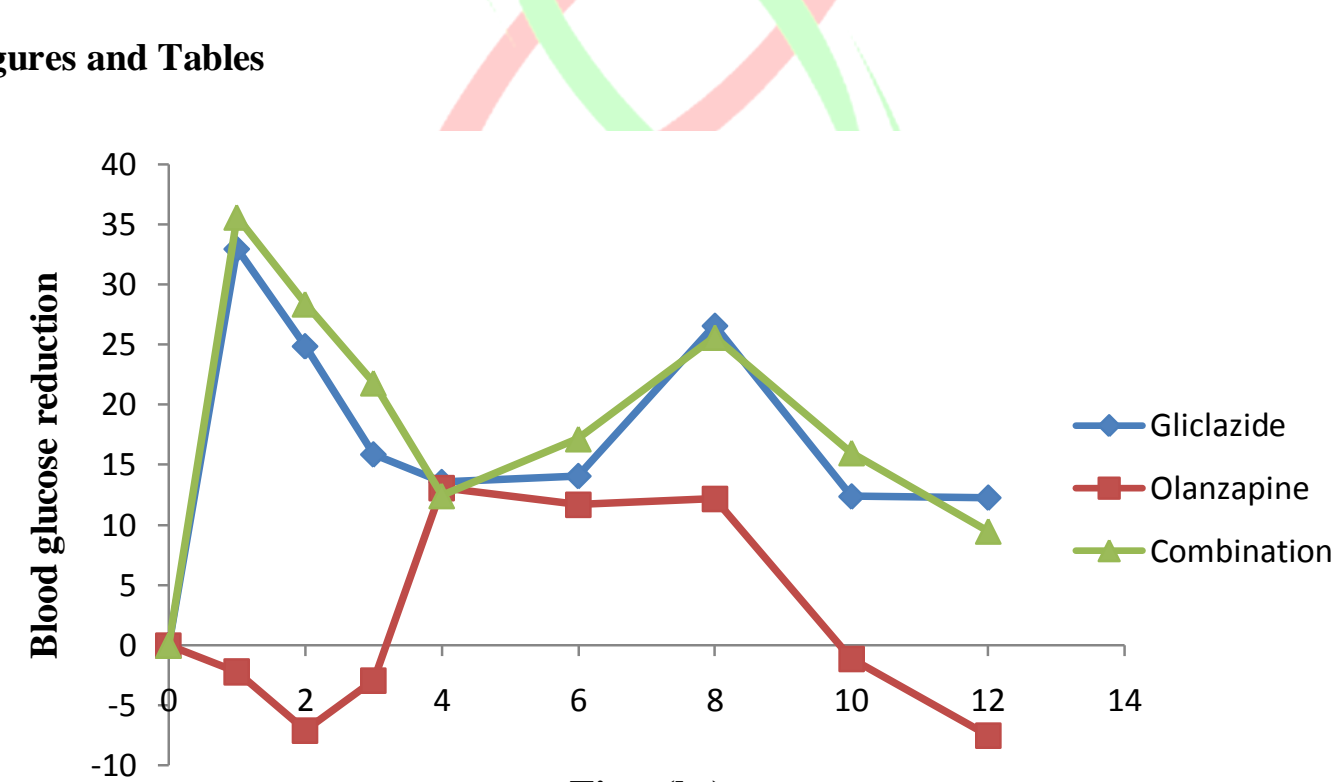

Time (hr)

Fig 1: Average percent blood glucose reduction after administration of gliclazide, olanzapine and their combination in normal rats $(N=6)$ 
IOSR Journal of Pharmacy

Vol. 1, Issue 1, Nov.-Dec, 2012, pp. 035-043

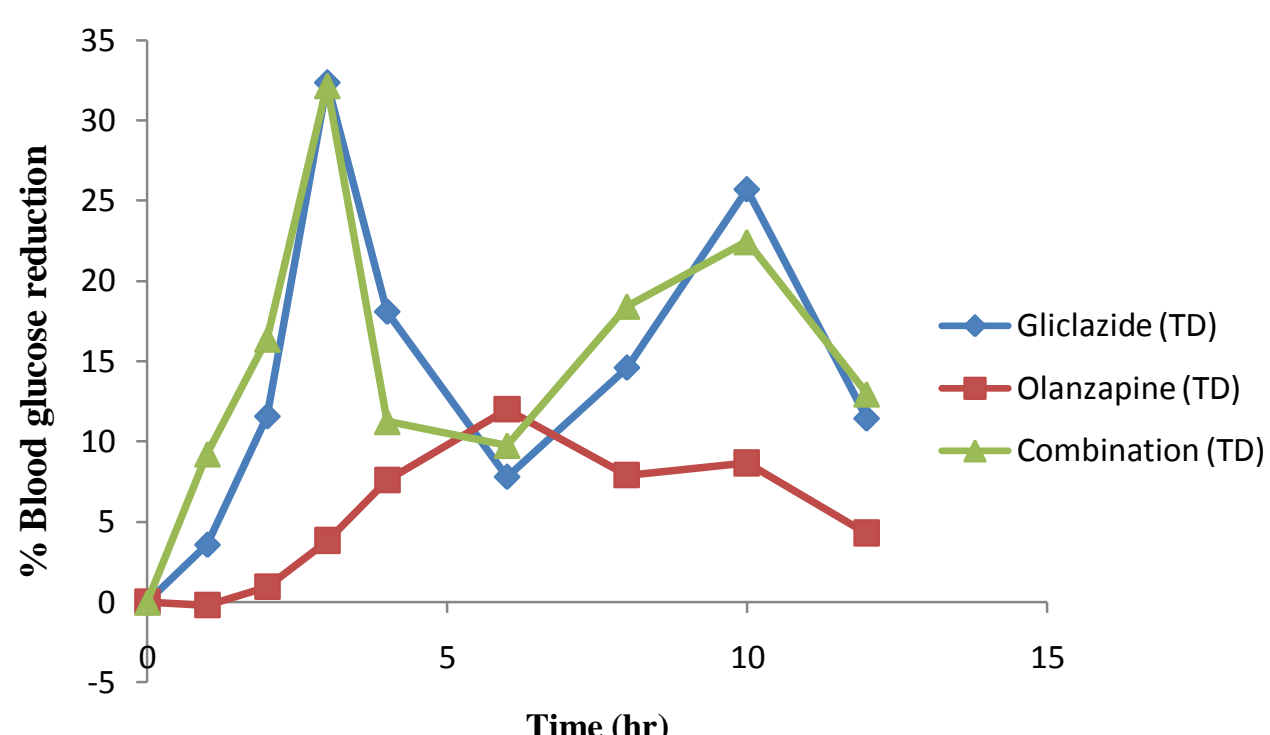

Fig 2: Average percent blood glucose reduction after administration of gliclazide, olanzapine and their combination in diabetic rats $(N=6)$

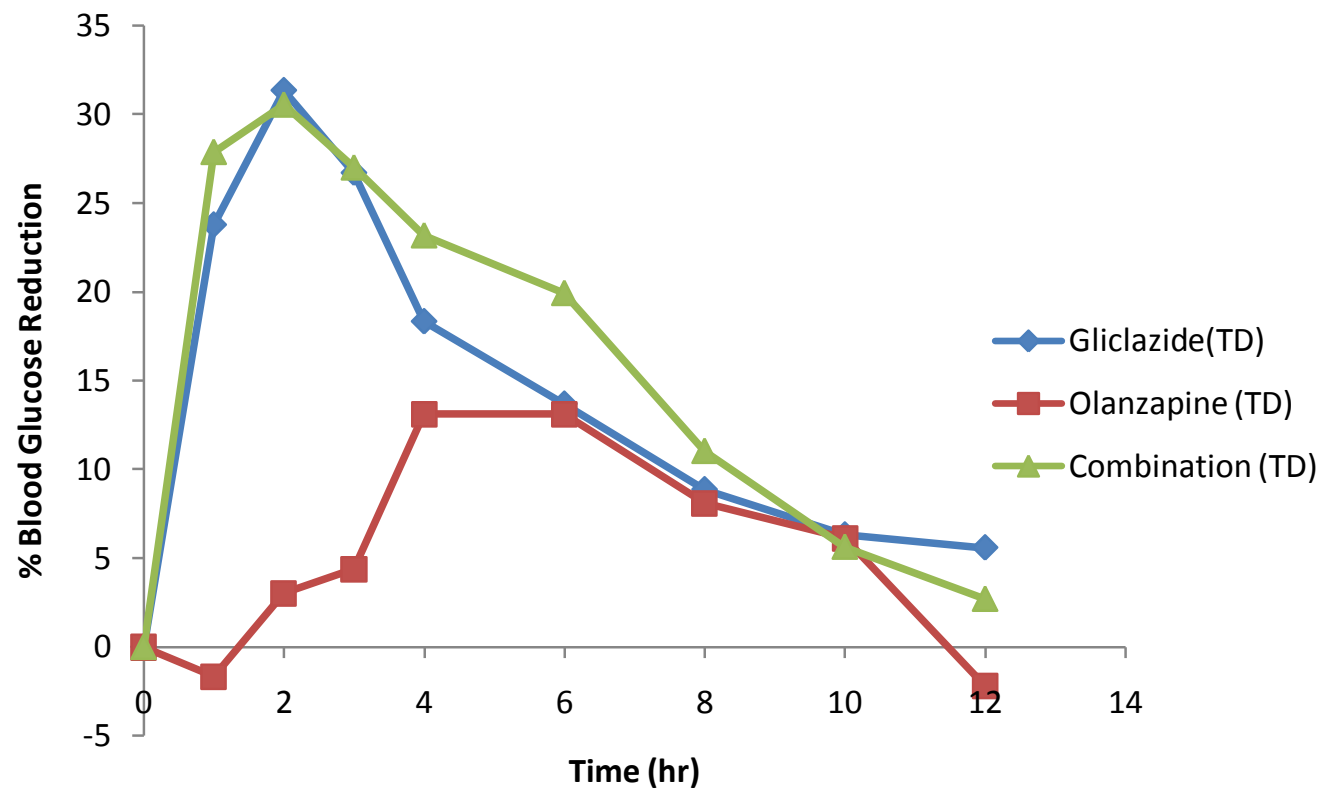

Fig 3: Average percent blood glucose reduction after administration of gliclazide, olanzapine and their combination in normal rabbits $(N=4)$ 


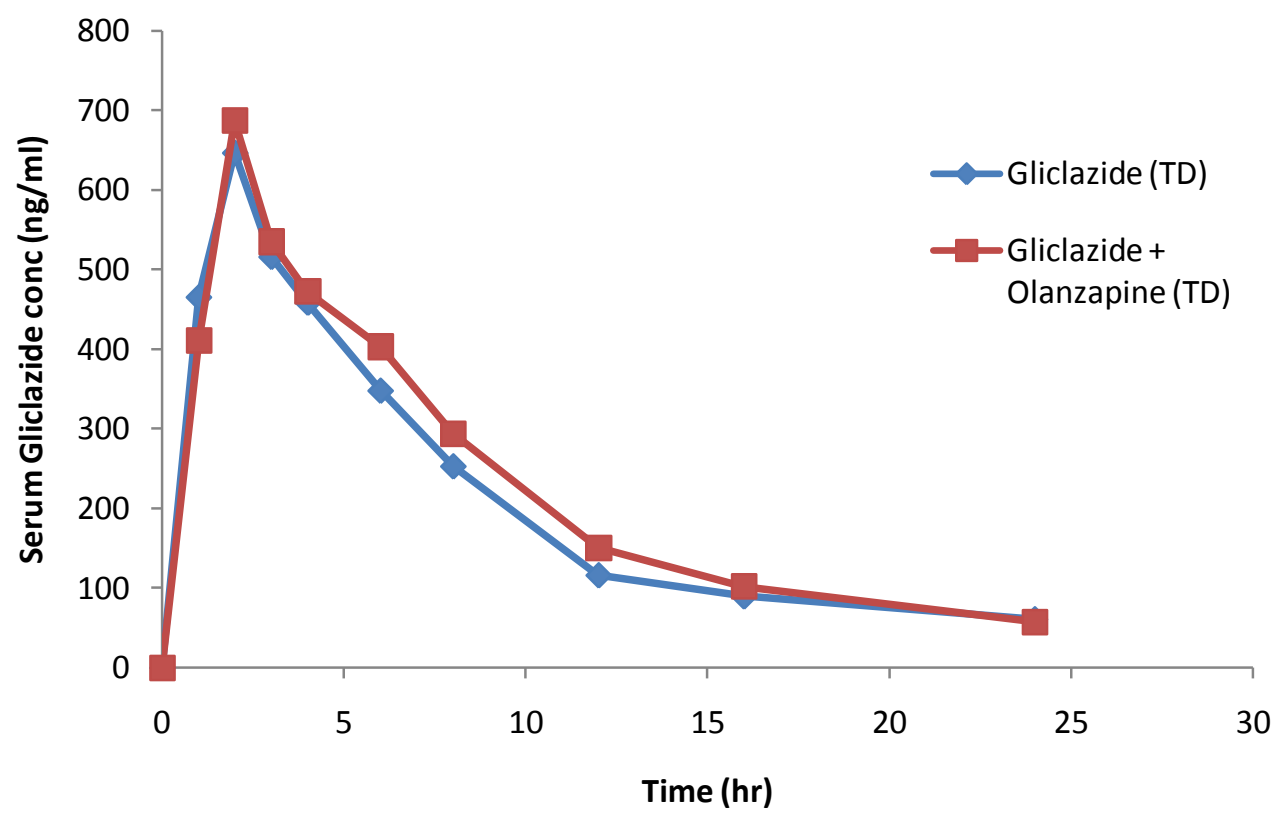

Fig 4: Average serum gliclazide concentration $(\mathrm{ng} / \mathrm{ml})$ without and with Olanzapine treatment in normal rabbits $(N=4)$

Table 1: Average percent blood glucose reduction after administration of gliclazide, olanzapine and their combination in normal/diabetic rats $(\mathrm{N}=6)$

\begin{tabular}{|c|c|c|c|c|c|c|}
\hline \multirow{2}{*}{ Time (h) } & \multicolumn{3}{|c|}{ Normal rats } & \multicolumn{3}{c|}{ Diabetic rats } \\
\cline { 2 - 7 } & Gliclazide & Olanzapine & $\begin{array}{c}\text { Gliclazide }+ \\
\text { Olanzapine }\end{array}$ & Gliclazide & Olanzapine & $\begin{array}{c}\text { Gliclazide }+ \\
\text { Olanzapine }\end{array}$ \\
\hline 0 & 0 & 0 & 0 & 0 & 0 & 0 \\
\hline 1 & $\mathbf{3 3 . 0} \pm \mathbf{2 . 8}$ & $-2.20 \pm 0.98$ & $\mathbf{3 5 . 5 1} \pm \mathbf{1 . 7}$ & $3.58 \pm 1.68$ & $-0.19 \pm 0.42$ & $9.23 \pm 2.04$ \\
\hline 2 & $24.9 \pm 4.4$ & $-7.10 \pm 1.34$ & $28.40 \pm 3.2$ & $11.58 \pm 3.41$ & $1.88 \pm 1.6$ & $16.38 \pm 1.92$ \\
\hline 3 & $15.9 \pm 6.0$ & $-2.95 \pm 1.01$ & $23.50 \pm 1.2$ & $\mathbf{3 2 . 3 6} \pm \mathbf{4 . 5 5}$ & $3.56 \pm 0.59$ & $\mathbf{3 2 . 1 7} \pm \mathbf{0 . 6 6}$ \\
\hline 4 & $16.4 \pm 4.8$ & $\mathbf{1 3 . 1 1} \pm \mathbf{2 . 7 7}$ & $12.45 \pm 2.3$ & $18.1 \pm 3.01$ & $7.6 \pm 1.52$ & $11.25 \pm 1.43$ \\
\hline 6 & $17.7 \pm 5.1$ & $11.76 \pm 3.24$ & $22.43 \pm 3.1$ & $7.81 \pm 0.96$ & $\mathbf{1 2 . 0} \pm \mathbf{0 . 9 1}$ & $9.76 \pm 2.08$ \\
\hline 8 & $\mathbf{2 6 . 6} \pm \mathbf{4 . 8}$ & $12.25 \pm 3.83$ & $\mathbf{2 5 . 5 8} \pm \mathbf{3 . 1}$ & $14.61 \pm 4.64$ & $7.91 \pm 2.14$ & $18.43 \pm 2.21$ \\
\hline 10 & $12.4 \pm 3.7$ & $-1.18 \pm 2.63$ & $16.05 \pm 2.6$ & $\mathbf{2 5 . 7 1} \pm \mathbf{3 . 2 4}$ & $8.66 \pm 2.08$ & $\mathbf{2 2 . 4 5} \pm \mathbf{2 . 7 5}$ \\
\hline 12 & $12.3 \pm 3.7$ & $-7.54 \pm 2.53$ & $12.04 \pm 2.5$ & $11.45 \pm 2.41$ & $4.3 \pm 1.32$ & $12.96 \pm 0.56$ \\
\hline
\end{tabular}

Mean \pm SEM; *** Significant at $P<0.001$; ** Significant at $P<0.01$; Significant at $P<0.05$ compared to gliclazide control 
IOSR Journal of Pharmacy

Vol. 1, Issue 1, Nov.-Dec, 2012, pp. 035-043

Table 2: Average percent blood glucose reduction after administration of gliclazide, olanzapine and their combination in normal rabbits $(\mathrm{N}=4)$

\begin{tabular}{|c|c|c|c|}
\hline Time $(\mathrm{h})$ & Gliclazide & Olanzapine & Gliclazide + Olanzapine \\
\hline 0 & 0 & 0 & 0 \\
\hline 1 & $23.80 \pm 3.58$ & $-1.65 \pm 1.03$ & $27.950 \pm 0.42$ \\
\hline 2 & $\mathbf{3 1 . 3 7} \pm \mathbf{0 . 5 3}$ & $4.30 \pm 1.60$ & $\mathbf{3 0 . 5 7 \pm \mathbf { 0 . 4 4 }}$ \\
\hline 3 & $26.72 \pm 1.48$ & $4.37 \pm 1.71$ & $27.02 \pm 2.70$ \\
\hline 4 & $18.35 \pm 3.54$ & $\mathbf{1 3 . 1 1} \pm \mathbf{1 . 9 1}$ & $23.20 \pm 3.11$ \\
\hline 6 & $13.70 \pm 2.77$ & $13.10 \pm 1.74$ & $19.95 \pm 2.86$ \\
\hline 8 & $8.87 \pm 2.64$ & $8.10 \pm 1.49$ & $11.05 \pm 1.49$ \\
\hline 10 & $6.32 \pm 2.46$ & $6.11 \pm 2.11$ & $5.65 \pm 0.74$ \\
\hline 12 & $5.60 \pm 2.09$ & $-2.17 \pm 1.89$ & $2.71 \pm 1.05$ \\
\hline
\end{tabular}

Mean $\pm S E M$; *** Significant at $P<0.001$; ** Significant at $P<0.01$; * Significant at $P<0.05$ compared to gliclazide control

Table 3: Average serum gliclazide concentration $(\mathrm{ng} / \mathrm{ml})$ without and with Olanzapine treatment in normal rabbits $(\mathrm{N}=4)$

\begin{tabular}{|c|c|c|}
\hline Time $(\mathrm{h})$ & Gliclazide & Gliclazide +Olanzapine \\
\hline 0 & 0 & $410.50 \pm 26.63$ \\
\hline 1 & $465.62 \pm 44.19$ & $686.87 \pm 4.84$ \\
\hline 2 & $646.87 \pm 34.58$ & $534.87 \pm 4.85$ \\
\hline 3 & $516.25 \pm 29.46$ & $472.50 \pm 5.52$ \\
\hline 4 & $458.75 \pm 23.57$ & $403.0 \pm 9.04$ \\
\hline 6 & $348.12 \pm 25.66$ & $294.12 \pm 2.12$ \\
\hline 8 & $253.12 \pm 31.95$ & $150.87 \pm 4.42$ \\
\hline 12 & $116.25 \pm 18.41$ & $102.0 \pm 2.80$ \\
\hline 16 & $89.68 \pm 9.92$ & $57.12 \pm 1.0$ \\
\hline 24 & $61.00 \pm 12.17$ & \\
\hline
\end{tabular}


IOSR Journal of Pharmacy

Vol. 1, Issue 1, Nov.-Dec, 2012, pp. 035-043

Mean \pm SEM; *** Significant at $P<0.001$; ** Significant at $P<0.01$; * Significant at $P<0.05$ compared to gliclazide control

Table 4: Mean pharmacokinetic parameters of gliclazide before and after olanzapine administration in rabbits $(\mathbf{N}=\mathbf{4})$

\begin{tabular}{|l|l|l|}
\hline Pharmacokinetic parameter & Without Olanzapine & With Olanzapine \\
\hline $\mathrm{AUC}_{0-24}(\mathrm{ng} / \mathrm{ml} / \mathrm{h})$ & $5019.62 \pm 57.21$ & $5313.38 \pm 135.96$ \\
\hline $\mathrm{AUC}_{0-\alpha}(\mathrm{ng} / \mathrm{ml} / \mathrm{h})$ & $5614.29 \pm 166.14$ & $5779.87 \pm 165.73$ \\
\hline $\mathrm{AUMC}_{0-24}(\mathrm{ng} / \mathrm{ml} / \mathrm{h} * \mathrm{~h})$ & $37395.57 \pm 4171.14$ & $36840.04 \pm 1249.82$ \\
\hline $\mathrm{AUMC}_{0-\alpha}(\mathrm{ng} / \mathrm{ml} / \mathrm{h} * \mathrm{~h})$ & $57632.27 \pm 10822.18$ & $52124.54 \pm 2260.53$ \\
\hline $\mathrm{K}_{\mathrm{e}}\left(\mathrm{h}^{-1}\right)$ & $0.101 \pm 0.007$ & $0.114 \pm 0.00$ \\
\hline $\mathrm{K}_{\mathrm{a}}\left(\mathrm{h}^{-1}\right)$ & $2.30 \pm 0.0$ & $2.3 \pm 0$ \\
\hline $\mathrm{t}_{1 / 2}(\mathrm{~h})$ & $6.91 \pm 0.49$ & $6.0525 \pm 0.07$ \\
\hline $\mathrm{V}_{\mathrm{dss}}(\mathrm{ml} / \mathrm{kg})$ & $6390.06 \pm 850.95$ & $5588.1 \pm 119.02$ \\
\hline $\mathrm{Cl}(\mathrm{ml} / \mathrm{h} / \mathrm{kg})$ & $753.73 \pm 40.96$ & $652.47 \pm 19.40$ \\
\hline $\mathrm{C}_{\max }(\mathrm{ng} / \mathrm{ml})$ & $646.87 \pm 34.58$ & $2 \pm 0$ \\
\hline $\mathrm{T}_{\max }(\mathrm{h})$ & $2.0 \pm 0.0$ & $668 \pm 21.62$ \\
\hline $\mathrm{MRT}(\mathrm{h})$ & $10.14 \pm 1.58$ & $9.00 \pm 0.15$ \\
\hline
\end{tabular}

Mean \pm SEM; *** Significant at $P<0.001$; ** Significant at $P<0.01$; Significant at $P<0.05$ compared to gliclazide control

\section{Conclusion}

When pharmcodynamics response was considered, single dose treatment of olanzapine did not alter the hypoglycemic response produced by gliclazide in rabbits and rats. Since olanzapine has not altered gliclazide response it appears that olanzapine has no influence on the pancreatic and extra pancreatic (cellular utilization of glucose) mechanisms that influence blood glucose. There was no significant change in pharmacokinetic parameters of gliclazide in presence of olanzapine in normal rabbits. Hence it is concluded that single dose treatment with olanzapine has no influence on pharmacodynamics/ pharmacokinetics of gliclazide. Since the combination was found to be safe in two dissimilar species, the combination was assumed to be safe in humans also.

\section{Acknowledgments}

The authors are thankful to Micro labs, Bangalore and Suraksha Pharmaceuticals Pvt Ltd., for supplying gift samples of gliclazide and olanzapine respectively. The authors are also thankful to Dr. D.R. Krishna for providing kinetics software Ramkin for calculation of kinetic parameters.

\section{REFERENCES}

[1] Ryan J. Anderson, Kenneth E. Freedland, Ray E. Clouse and Patrick J. Lustman, Diabetes Care, 24(6), 2001, 1069-1078.

[2] Dora kohen, Diabetes mellitus and schizophrenia: historical perspective, The British Journal of Psychiatry 184(47), 2004, s64-s66. 
[3] 'Schizophrenia and Diabetes 2003', Expert Consensus Meeting, Dublin, 3-4 October 2003, Summary, The British Journal of Psychiatry, 184(47), 2004, 112-114.

[4] J.M. Meyer, Effects of atypical antipsychotics on weight gain and serum lipid levels. J Clin Psychiatry, 62(27), 2001, 27-34.

[5] T. Heiskanen, L. Niskanen, R. Lyytikainen, P.I Saarinen and J. Hintikka, Metabolic syndrome in patients with schizophrenia, J Clin Psychiatry, 64(5), 2003, 575-9.

[6] G. Schernthaner, Gliclazide modified release: A critical review of pharmacodynamic, metabolic and vasoprotective effects, Metabolism, Aug 52 (8 suppl 1), 2003, 29-34.

[7] D.K. Song and F.M Ashcroft, Glimepiride block of cloned $\beta$ cell, cardiac and smooth cell $\mathrm{K}^{+}$ATP channels, Br J Pharmacol, 133(1), 2001,193-99.

[8] F.M. Gribble, S.J Tucker, S. Seino and F.M. Ashcroft, Tissue specificity of sulfonylureas: studies on cloned cardiac and beta-cell K ${ }^{+}$(ATP) channels. Diabetes, 47(9), 1998, 1412-18.

[9] P.E Jennings and JJF. Belch, Free radical scavenging activity of sulfonylureas: A clinical assessment of the effectiveness of gliclazide. Ter Arkh, 73(4), 2001, 27-31.

[10] R.C. Brein, M. Luo, N. Balazs and J. Mercuri, In vitro and in vivo antioxidant properties of gliclazide. $J$ Diabetes Complications, Jul-Aug 14(4), 2000, 201-6.

[11] B. Holmes, R.C. Heel, R.N. Brogden, T.M. Speight and G.S. Avery, Gliclazide: A preliminary review of its pharmacodynamic properties and therapeutic efficacy in diabetes mellitus, Drugs, Apr 27(4), 1984, 301-327.

[12] A.D. Harrower, Efficacy of gliclazide in comparison with other sulphonylureas in the treatment of NIDDM, Diabetes Res Clin Pract, 14( Suppl 2), 1991, S65-7.

[13] A.D. Harrower, Comparative tolerability of sulfonylureas in diabetes mellitus, Drug Safety, Apr 22(4), 2000, 313-20.

[14] O. Ziegler and P. Drouin, Hemobiological properties of Gliclazide, J diabetes complications, Oct-Dec; 8(4), 1994, 235-9.

[15] K.J. Palmer and R.N. Brogden, Gliclazide: an update of its pharmacological properties and therapeutic efficacy in non-insulin-dependent diabetes mellitus, Drugs. 46(1), 1993, 92-125.

[16] D. Fava, M. Cassone-Faldetta, O. Laurenti, O. De luca, A. Ghiselli and G. De Mattia, Glicalzide improves antioxidant status and nitric oxide mediated vasodialation in type-2 diabetes, Diabet Med. 19(9), 2002, 752-7.

[17] Kilari Eswar Kumar and Shaik Mastan, Effect of protease inhibitors (indinavir and ritonavir) on the pharmacokinetics of gliclazide in rabbits, Research and Reports in Endocrine Disorders, 1(1), 2001, 19 .

[18] K. Eswar Kumar, A. Ramesh and S. Satyanarayana, Pharmacodynamic and Pharmacokinetic Drug Interaction of Gliclazide and Lacidipine in Animal Models, Indian J.Pharm. Educ. Res. 42(3), Jul.Sep. 2008.

[19] S. Satyanarayana and Eswar K. Kilari, Influence of nicorandil on the pharmacodynamics and pharmacokinetics of gliclazide in rats and rabbits. Mol Cell Biochemt. 291(1-2), 2006, 101-5.

[20] S. Satyanarayana, M.S. Chandrasekhar, O. Palakshi Gouda and K. Eswar Kumar, Drug-Drug Interaction between Pravastatin and Gliclazide in Animal Models. Scholarly Research Exchange, vol 2008, 2008.

[21] SK. Mastan and K Eswar Kumar, Influence of non-nucleoside reverse transcriptase inhibitors (efavirenz and nevirapine) on the pharmacodynamic activity of gliclazide in animal models. Diabetology \& Metabolic Syndrome, 1(15), 2009.

[22] D.B. Campbell, R. Lavielle and C. Nathan, The mode of action and clinical pharmacology of gliclazide: a review. Diabetes Res Clin Pract, 14(suppl 2), 1991, S21-S36.

[23] Product information: Zyprexa®, Olanzapine tablets, Eli Lilly and company, USA, 2003.

[24] P. Trinder, Determination of blood glucose using an oxidase-peroxidase system with a non carcinogenic chemogen, J Clin Pathol, 22, 1969, 158-61.

[25] R.E. Heikkila, The prevention of alloxan-induced diabetes in mice by dimethyl sulfoxide, Eur $J$ Pharmacol, 44(2), 1988, 191-93.

[26] K. Eswar Kumar, A. Ramesh, R. Surendra yadav and S. Satyanarayana, Determination of gliclazide in rabbit serum by RP-HPLC. Acta Ciencia Indica, 33(3), 2007, 273-78.

[27] F.M. Gribble and F. Reimann, Differential selectivity of insulin secretogogues: mechanism, clinical implications and drug interactions, J. Diabetes complications, Mar-Apr 17(2), 2003, 11-5. 
[28] A.S. Rajan, L. Aguilar-Bryan, D.A. Nelso, G.C. Yaney, W.H. Hsu, D.l. Kunze, AE. Boyd, Ion channels and insulin secretion, Diabetes care, 13(3), 1990, 340-63.

[29] H. Miyazaki, T. Fijii, K. Yoshida, S. Arakawa and H. Furukawa, Disposition and metabolism of ${ }^{3} \mathrm{H}$ gliclazide in rats. Eur J Drug Metab Pharmacokinet, 8(2), 1983, 117-31.

[30] A. Benakis and B. Glasson, Metabolic study of ${ }^{14} \mathrm{C}$-labelled gliclazide in normal rats and in rats with streptozotocin-induced diabetes, in Gliclazide and Treatment of Diabetes, Ed, H. Keen, London: Academic Press and the Royal Society of Medicine, 1980, 57-69.

[31] D.E. Rollins and C.D. Klaassen, Biliary excretion of drugs in man, Clin Pharmacokinet. 4(5), 1979, 368-79.

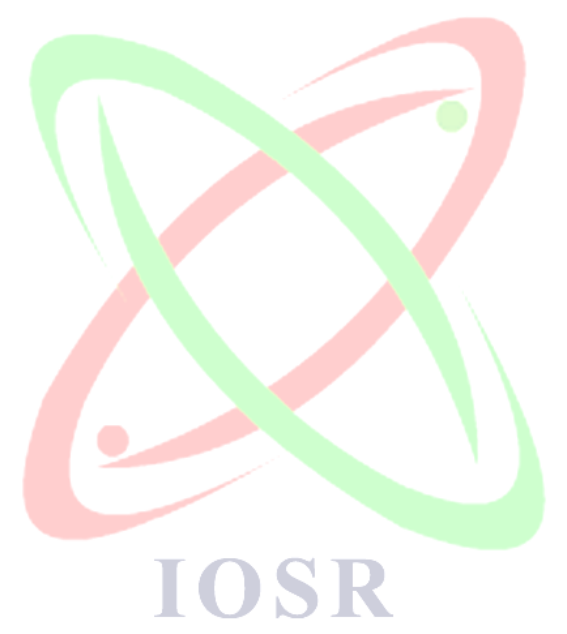

